\title{
Research Paper Performance of inputs used in Indian agriculture
}

See end of the paper for authors' affiliations

Correspondence to :

V.J. RATHOD

Department of

Agricultural Economics and Statistics, College of

Agriculture, Dr. Panjabrao Deshmukh Krishi

Vidyapeeth, AKOLA (M.S.) INDIA

Paper History :

Received : 23.04.2015;

Revised : 22.06.2015;

Accepted : 21.07.2015
Abstract : Agriculture is the backbone of Indian economy. Its contribution to the overall Gross Domestic Product (GDP) of the country has fallen from about 30 per cent in 1990-91 to less than 13.7 per cent in 2012-13. To enhance productivity, easy and reliable access to inputs such as quality seeds, fertilizers, pesticides, herbicides, fungicides, plant growth regulators, access to suitable technology tailored for specific needs, the presence of support infrastructure and innovative marketing systems to aggregate and market the output from large number of small holdings efficiently and effectively are necessary. The objectives of the study was to assess the quantum of inputs used in Indian Agriculture, To study the availability of NPK fertilizers, To study the performance of inputs used in Indian Agriculture and To assess the growth in inputs used in Indian Agriculture. The relevant information was gathered through secondary data for the period 1991-92 to 2010-11 on various inputs used in agriculture were collected from the website of Food and Agriculture Organization (FAO statistics). Compound growth rate, simple averages and co-efficient of variation were used for the analysis of data. The study reveals that the use of seeds and fertilizers in Indian Agriculture has been increased in its quantum and compound growth rates for seeds and fertilizer also significant. Certified seed is dominating in overall period while nitrogenous fertilizers dominating in fertilizer consumption. There was highest variation in use of seed, plant growth regulators and import of fertilizers. There is need to increase the utilization of quality seed to improve the productivity. Increase the production of fertilizers so that the cost on import should be minimized.

KEY Words : Performance, Fertilizer consumption, Inputs, Compound growth rate

How To Cite This PAper : Rathod, V.J., Bondhare, V.O. and Choudhary, Ramjilal (2015). Performance of inputs used in Indian agriculture. Internat. Res. J. Agric. Eco. \& Stat., 6 (2) : 293-299. 